\title{
Psychopathology of Dementia: Psychology's Pivotal Role
}

\author{
Mario Dominic Garrett
}

\section{ABSTRACT}

Biology does not completely explain dementia. We can neither predict nor confirm a diagnosis of dementia based purely on its biology. Recent studies looking at prevention using social interventions hold better promise for ameliorating the disease. Yet, we do not have a major theory to explain these outcomes without resorting to biology. By understanding that there are mediating and moderating psychological factors promoting dementia, we take a broader view of the disease than a simple binary approach. Psychology plays a vital role in this clinical disease, in how cognition affects dementia. The presumption is that all of cognition: perception, orientation, novelty, attention, the application of knowledge (praxis), calculation, language, abstract thinking, and memory can affect and bring about dementia. It is not dementia that causes cognitive decline but cognitive decline that causes dementia. The psychopathology of dementia can initiate dementia, moderate it by enhancing or retarding the progression of the disease or mediate the disease by acting as a confirmatory process. The tipping point expressed by apathy and depression heralds a change in cognition. The psychopathology of dementia is important in understanding the etiology of dementia as it holds the most promising avenue for curing some dementias.

Keywords: Dementia 1, stereotypes 2, nocebo 3.

\author{
Submitted : September 2, 2021 \\ Published : October 20, 2021 \\ ISSN: $2593-8339$ \\ DOI: $10.24018 /$ ejmed.2021.3.5.1039 \\ M. D. Garrett \\ San Diego State University, USA \\ (e-mail: mgarrett@sdsu.edu)
}

*Corresponding Author

\section{INTRODUCTION}

A century of failures in finding a cure to Alzheimer's disease has not deterred the U.S. National Institute on Aging (NIA) from supporting a monolithic theory based on neuritic plaques and neurofibrillary tangles as causal agents [1], [2]. Despite evidence that pharmacological compounds that clear these plaques from the brain do not improve cognition but worsen it [3]-[7], the biological theory survives refutation. Doubling down, the NIA now proposes ignoring the clinical evidence completely and relying exclusively on these failed biomarkers to determine the presence of this clinical disease. NIA is using Alzheimer's disease as the first test case to push for a purely biological nosology of a behavioral disease. What is worrying is that science does not support this belief.

Diagnosing a mental disease, such as dementia based on biological markers is the holy grail of psychiatry. Many powerful forces are pushing for this change through the Research Domain Criteria (RDoC) framework [8]. However, the evidence contradicts such aspirations, especially among older people. Plaques and tangles are not consistently correlated with Alzheimer's disease or dementia. Half of clinically diagnosed oldest-old with dementia have insufficient neuropathology to account for their dementia [9], [10] while thirty to fifty percent of older adults without dementia meet the neuropathological criteria for Alzheimer's disease [11]-[17]. The neuropathology of dementia is so common that it is found in all adults [18]. Among older people, the correlation between Alzheimer's disease neuropathology and its clinical expression declines [19]. It is disturbing that we have known this fallacy for more than a century [20]. By ignoring the science and following a political path, the NIA relinquished its leadership role and in response to this vacuum, research has independently started looking at social interventions as preventive measures rather than a pharmacological cure.

Small-scale studies that showed efficacy in improving cognition through social intervention [21], [22], were quickly followed by a multi-center, large clinical trials. The Finnish Geriatric Intervention Study to Prevent Cognitive Impairment and Disability (FINGER) showed that behavioral intervention can reduce dementia by a quarter [23]. An efficacy higher than any drug. The FINGER protocol, currently being implemented in twenty-five countries, is the first global study looking at social ways to reduce dementia risk [24]. Within a few years, the improvements through these lifestyle changes have already surpassed fifty years of pharmacological attempts at eradicating the disease. An achievement to celebrate, not because we have found a panacea but because we have corrected our course of action and we are now heading towards a broader appreciation of the causes of dementia. However, to mute the jubilation, there are still about $75 \%$ of cases of dementia that remain unaffected by these interventions.

The many biological causes of dementia [25] suggest that in addition to psychology, there might also be biological 
moderators and/or mediators that are influencing the progression of the disease. The most biologically significant are vascular and inflammatory conditions that bring about a cascade of negative biological sequelae resulting in dementia. It is extremely rare for a dementia diagnosis not to be accompanied by other morbidities. There are very few cases of pure dementias. Common pathologies are shared between dementia with Lewy bodies and Alzheimer's disease [26], Alzheimer's disease and Parkinson's disease [27], and Alzheimer's disease and vascular dementia [28]. Dementia is a "common final pathway" that has many and multiple causes. Rather than looking at sole causes we need to approach dementia as a Complexity Theory problem [29]. Even with all this knowledge, iatrogenic dementiaunknown causes of dementia - still characterizes dementia research as a great expanse of unknowns remain to be explored.

\section{Role OF Psychology}

Although focusing on prevention rather than cure is a timely correction - adjusting our research trajectory in the right direction - the future of research in dementia requires not only radical thinking but comprehensive thinking. Looking for binary answers as the sole cause of the disease ignores factors that might mediate and/or moderate the disease process. In the last fifty years, epigenetics has taught us the importance of these environmental mediating and moderating factors in biology [30]. Besides, we know how significant psychological influences are on our biology through placebo and nocebo research that is now a necessary protocol in all medical and clinical trials [31]. Future dementia research requires consolidation of all three approaches of medical, clinical, and theoretical - psychiatry, psychology, and psychoanalysis. Prevention techniques using behavioral instead of pharmacological interventions, highlight the moderating and mediating aspects of dementia's disease progression. These behavior modifications are important to understanding the global clinical expression of dementia.

Older adults, because of age and their accumulated experience, have developed a complex and reliable model of their environment - an isomorphic representation [32]. Isomorphic relates to a model of the world that corresponds in form and function to the world around us - making a true representation of the world we live in. When it comes to problem-solving, older adults are more likely to rely on these extensive, and unconscious experiences rather than consciously looking at the environment for answers. This experience, based on past successes and failures, predicates how current issues are approached in order to solve problems successfully [33]. Eventually, this isomorphic representation becomes so well developed and self-reliant that we stop looking for input from outside. In older ages, global cognition becomes compromised, and this tipping point is the psychopathology beginnings of dementia, affecting all components of cognition. We can see how older adults "fall" into dementia by behaving in ways that promote negative cognition and explains why age remains the most important contributor to dementia.
Cognition is defined as thinking processes involving perception, attention, novelty, application of knowledge (praxis), calculation, language, abstract thinking, orientation, and memory. Although memory is usually the obvious culprit in dementia research, studies suggest that there are no significant relationships between cognitive tests and the incidence of dementia in participants without global cognitive impairment [34]. Other than global cognitive impairment there is no single test, including memory that differentiates dementias with any accuracy. Tests tend to measure severity rather than specificity. Although memory deficits are not universal in dementia as they are in Alzheimer's disease, memory is a lynchpin in the psychopathology of dementia, as we shall see. The remaining components of cognition are all affected by the psychopathology of dementia. There is ample evidence showing how all these cognitive components act as mediating and/or moderating influences on dementia since they lead to a cascade of negative consequences. While each part of cognition is discussed individually, it becomes clear that these components are intimately interconnected.

\section{A. Perception}

When looking at a picture, older participants spend more time scanning a small "useful" area of an image, while younger participants scan images more evenly [35]. Becoming aware that most solutions to current problems reside in our memories, the brain unconsciously reduces learning from the environment and relies more heavily on this isomorphic representation. Psychopathology of dementia involves a "change" in our cognition, including our perception, memory, attention, and orientation to fit a coherent narrative that we have adopted. In one study participants needed to be attentive to one of two groups of players by counting the number of times the three players in one group pass a ball among themselves. While counting, a person in a gorilla costume enters and then leaves the background. Around half of people will simply not "see" the gorilla [36]. We are unlikely to see events that do not conform to our "essential" task at hand. One study shows how our perceptual biases change what we see especially when we are focusing and anticipating a specific outcome. Many other types of biases change our perception including Change Blindness, Inattentional Blindness, Comparison Blindness, and Repetition Blindness, all expose this increased bias with age. We start perceiving the world not as it is but more as we know it is. We look at the world with anticipation that precludes perception. We become affirming rather than inquisitive agents.

\section{B. Attention}

Attention allows us to focus on a specific issue. As we get older and become more affirming agents, our attention becomes dictated by expectation rather than by external conditions. We are attentive to things that we expect to be important rather than how they appear today. A typical problem with attention among older adults is driving. Most older adults have been driving for decades and as a result, they have amassed a great deal of experience. We would expect them to be excellent drivers by the time they reach 65 years of age. But this experience works against them. As a group, and considering mileage driven, older drivers have higher rates of automobile crashes and driving violations 
[37]. Although on an individual basis these driving outcomes are not higher than that of younger drivers [38], older adults mitigate their diminishing driving capacity by restricting driving in particular situations, such as restricting driving at night, in poor weather, when the roads are busy, and on highways [39]. One of the problems is not their driving per se but their attention. Older adults are attentive to aspects of a visual field that they think, from past experiences, deserve their attention. They orient themselves to "useful" information in what is known as a useful field of view (UFOV). UFOV explains how older adults become accustomed to relying on their expectations rather than the conditions on the ground [40]. They orient themselves only to what they consider useful, and this works well until something unexpected happens. This also reflects activities in daily life as most older adults orient themselves into a tunnel vision, mostly unconscious and involving more control and inhibition.

\section{Novelty}

As our isomorphic representation becomes more complex and comprehensive, and as we increasingly affirm our interpretation of the world, we begin to shun novelty as we already know the answer. Novelty requires attention, memory, and learning that are all resource-intensive activities. Although there is no empirical evidence showing that conservatism promotes dementia, studies are showing the obverse that novelty-seeking reduces dementia. The frequency of learning new skills, taking up new hobbies, or learning about a new subject reduced the chances of the disease by one in four [41]. Various other novel interventions such as playing strategy video games [42] and cognitive and perceptual-motor activities [43], group problem solving [44], helping children with reading, classroom behavior, and library support [45], giving piano lessons [46], and engaging in group discussions [47] all showed beneficial effects on cognitive out-comes [48]. Novelty is the antithesis of our isomorphic representation and challenges our affirming biases.

\section{Application of Knowledge (Praxis)}

Older adults become so efficient at engaging in regular activities (e.g., reading, driving, communicating, and talking) that changing this routine becomes difficult. The greater our ability the less open we are to looking at the world differently. This preferential bias was revealed with London taxi drivers. In one study, middle-aged men that learned directions to over 60,000 streets and 100,000 places of interest in the city paid a price for this proficient in one task, they lost their capacity to learn novel tasks [49]. The more proficient we become at one task, the less reliant we become on alternative approaches. All of this happens unconsciously, without awareness. As we get older, we develop complex skills that attract us away from learning novel ones. We not only affirm our knowledge base, but we also shy away from learning novel skills. Praxis is a double-edged sword, as we become proficient in one task, we are less likely to be able to learn an alternate one.

\section{E. Calculation}

Mathematical skills, in general, diminish quickly with age. Although healthy old people are impaired in numerosity discrimination such as the ability to distinguish many from few, most keep their arithmetical skills such as adding, subtracting, dividing, and multiplying [50]. In dementia the opposite is true where arithmetical skills diminish fast especially in an early stage of the disease [51]. Interestingly, numerical skills are disturbed more than reading and spelling in Alzheimer's disease [52]. In contrast, in some cases, numerical abilities remain preserved, despite impaired memory [53], or language disorders [54], suggesting that calculation is a different skill set and not related directly to dementia [55].

\section{F. Language}

In the Nun Study, a longitudinal study of 678 Catholic sisters 75 to 107 years of age who are members of the School Sisters of Notre Dame congregation, looked at the use of language over 50 years. What was found was that those novices who wrote autobiographical essays in very simple sentences died with symptoms of Alzheimer's, but none of those whose prose style was more complex succumbed to the disease [56]. Even in their 20s, problems with complex language had devastating clinical repercussions half a century later. Psychopathology starts early and has long-term consequences and different components of cognition are all affected like a house of cards.

\section{G. Abstract Thinking}

One of the early features of dementia, together with the initial awareness of short-term memory loss, is the loss of abstract thinking - the ability to think symbolically without the object being present. There is an age-related decrease in the ability to "regulate behavior on the basis of plans, abstract concepts, environmental feedback or one's own responses" [57]. Young children (between 5-7 years) more easily learn a wider variety of language sounds than adults [58] are better than adults at discriminating between unique faces (such as that of Barbary macaques) [59] and are more likely to look beyond the conventional uses of tools to solve problems [60]. Children learn causal relationships using only a handful of events, making far-reaching causal inferences easier and more quickly than adults [61]. Moreover, children were more likely than adults to generalize from two related and necessary causes rather than relying on prior assumptions. They pay more attention to available evidence. In contrast, older adults rely on their past knowledge - their isomorphic representation. Their model of the world has proved reliable in their past and they come to rely on it more than the current observation.

Abstract thinking cannot exist without memory, or calculation without attention, or perception without orientation. All cognitive components are interdependent, while abstract thinking is the foundation of an isomorphic representation. It forms Piaget's final stages of human development [62]. The essential idea from Piaget is the development of thinking about actions, to thinking in the abstract. As we get older, we aim to reflect the world in our isomorphic representation, from anticipating individual events to complete thought experiments and eventually actively constructing a comprehensive knowledgebase about the world we live in. This forms part of our orientation. 


\section{H. Orientation}

In cognition, orientation refers to being aware of time, place, and person. During a mental assessment you might get asked questions such as, where do you live, where are you right now, and who is the current president? Orientation is closely connected with all the other cognitive components and is one of the final attributes to diminish. That sense of self, that makes orientation important, fades with the diminishing of other cognitive components. While Reality Orientation Therapy delays nursing home placement and slows down the progression of cognitive decline in the early stages of dementia [63] it is indicative of a greater disconnect between our isomorphic representation and reality. We rely so much on our model of the world that we stop altogether taking input from the world around us.

\section{Memory}

Age-related memory deficits are common without dementia. Nevertheless, memory has attracted the most research in dementia compared to other cognitive components. Although there is no definitive test that distinguishes types of dementias, memory is the most obvious deficit as people first notice problems with their cognition as a result of problems with their short-term memory. However, despite the prevalence of memory deficits that do not result in dementia, it is now being proposed that such memory complaints in older adults should no longer be considered merely a normal age- related phenomenon but as an early sign of dementia [64]. Instead of narrowing the diagnosis of dementia interested parties are expanding it to include most older adults. By pathologizing aging we solidify stereotypes making the experience more emotive.

The more emotive an event, the easier the central features of the event are remembered, and peripheral details ignored [65]-[67]. As a downside, emotional events — although more memorable - are nevertheless more susceptible to distortion [68]-[70]. We easily accept memory loss as dementia and our cognitive biases confirm this expectation. We fill in the gaps. Distortion in memory becomes more likely under extreme emotional conditions compared to neutral conditions [71].

\section{DISCUSSION}

When we prefer experiences to learning, we sidestep the function of memory. As a result, we start noticing deficits in the first stage of memory - short-term memory. Problems in this early conduit of memory cause a cascade of bigger memory problems over time. For example, although retrieving information from our past is very efficient, it eventually subverts the role of learning. Memory's role is not just to recall past events, it is to recall past events so that we use these experiences as a lesson for the present, to better anticipate the future. We should ask not what memory is, but what memory is for [72]. If we follow this approach, then we realize that our lifetime goal of developing an isomorphic representation that is accurate and complete, will negate the function of learning novel items and therefore the role of memory. The better we become at this task the less we can learn new ones. Learning is how we interact and adapt to our surroundings. Memory allows for incremental learning. We recollect past experiences to predict the outcome. We build upon these experiences of predictions until we develop an isomorphic representation that is complex, comprehensive, and complete. But there is one problem with this development.

With dementia, there is a global deficit in all different components of cognition. These deficits come as a function of how we develop. They are developmental in that these deficits accumulate and progress as we become better at representing our world. The tipping point is how this slow global age-related deficit in cognition turns into a progressive, fast deterioration. Psychopathology can explain this tipping point. Once we rely on our accumulated experiences, our isomorphic representation, we stop learning and unconsciously reach a tipping point. The brain changes from looking for answers from the outside to looking for answers from our experiences. The self-reliance on our isomorphic representation ensures that the outside world becomes increasingly peripheral. By reducing learning, we stop using memory as intended, making memory increasingly redundant. Not that dementia affects cognition, but by reducing learning, cognition atrophies and progresses to dementia. It is the reduced reliance on cognition particularly memory, that causes dementia. This is the psychopathology of dementia that eventually influences bio-logical changes.

The psychopathology of dementia can initiate dementia, moderate it by enhancing or retarding the progressing of the disease or mediate the disease by expressing or suppress-ing the disease. The psychology of all these processes is the same, it follows a common final pathway of stopping learning, affecting short-term memory and later all aspects of memory that then affects all other cognitive components resulting in a degenerative dis-ease clinically expressed as dementia as a common final pathway.

\section{A. Initiate}

Initiate can start the process of the disease. Once we diagnose ourselves with dementia, or someone else with authority diagnose us with dementia, even when there is no, or little evidence, we easily conform to the stereotype [73]. These perceptual biases ensure that we ignore any proof that negates our self-assigned stereotype, or imposed stereotype. We only perceive events that support our judgment our narrative. Once we make these judgments it is difficult, if not impossible, to reverse - even if there is evidence to the contrary. Sadly, there is such a case and involves a 58-yearold woman who received a misdiagnosis of Alzheimer's disease by a neurologist who later had 26 malpractice suits filed against him and the hospital. But this patient did not know that at the time. Even when she was informed that her behavior is normal and that the neurologist made a mistake, this woman was convinced that the diagnosis was still correct [74]. Misleading feedback such as a diagnosis of dementia increases self-reported symptoms not just for dementia but also for health in general [75]. Although we would like to think that physicians are correct in diagnosing, a German study conducted a follow-up on diagnosis, confirmed Alzheimer dementia in only a third of cases (38\%) [76]. However, even when the diagnosis is inaccurate, the diagnosis by itself sets into motion all kinds of internal negative reactions in the patient. People who believe that their memory is failing will try and find a tipping point, and if not, 
in most cases, they will create one. They will recall that their memory was better before [77]. When such problems become more obvious, we try to rationalize these memory lapses and we find a ready-made stereotype: dementia. By assigning a term, we effectively create a tipping point when we unconsciously start to substantiate it, through the hundreds of different psychological biases.

One study looked at how we change our memories to accommodate an outcome (say a diagnosis.). This study measured how well-prepared students were for an exam before the exam and after receiving the bogus exam results. They found that those students that were randomly told they had good grades retrospectively reported more time studying, while those students that were randomly told they had a bad grade "remembered" less time studying than they reported earlier [78]. We rationalize and confirm our current situation as we see it, or on what we have been told. Just two biases create a powerful self-fulfilling strategy, by simultaneously narrowing our perception to see what we anticipate, and then rationalizing past experiences to substantiate this stereotype.

Such judgment rationalizes experiences that "something aberrant happened" starting a series of negative selfevaluation. As a construct, dementia is important in helping us define that tipping point. These are powerful unconscious processes that then promote a negative but coherent story. Creating a coherent story is part of our isomorphic representation a developmental stage that is impossible to eradicate.

\section{B. Moderate}

Moderate can enhance or diminish a process. Psychopathology of dementia is best seen as a moderating influence similar in its mechanism to the nocebo effect. In the most medically intensive units in hospital, the Intensive Care Units (ICUs) both placebos and nocebos are being employed to promote faster recovery. Medical staff in ICUs give patients positive reviews of their treatment applying suggestive techniques-based on future orientation, reframing, positivity, and supporting autonomy among many other positive suggestions - as part of their treatment. The outcome of these suggestive techniques is that patients get better faster [79]. Speedy and full recovery involves reducing ICU duration [80],[81], pain [82], post-operative complications [83], medications [84], and opioid use [85]. They approached the problem as both a nocebo and a placebo effect. Nocebo is when there is a negative expectation while placebo when there is a positive expectation. Before coming into the ICU unit, patients have a negative expectation that acts as a nocebo. With suggestive techniques, they reduced the nocebo and increased the placebo. In the context of dementia, other people keep reminding you of your deficits. The first question people with dementia hear is "Do you remember...?" And we take them to "memory cafes." Bibliographical evidence suggests that this stereotype threat acts as a nocebo where: "I feel I so often have to say I am sorry" [86]. Most people living with dementia are under a constant nocebo where those around them remind them constantly of their cognitive loss, especially memory loss. What is important is that even in ICUs, two-thirds of people who do not address their ICU traumas tend to have more nightmares, hallucinations, and paranoid delusions [87], indicating that trauma has long-term psychological sequela. Addressing trauma is therefore a therapeutic necessity and with dementia addressing their fears is the first step. Dementiaphobia the fear of getting dementia, needs to be approached as a nocebo.

Older people who report subjective cognitive decline are four times more likely to progress to dementia, and when others substantiate this stereotype, they are twice as likely to develop dementia [88]. This could mean that the memory loss is obvious because it is severe, but it could also show that a social diagnosis solidifies and promotes the stereotype. When other people — through stereotypes, expectations, and interactions - confirm these negative expectations they create a "consensus trance" that further promotes our negative self-evaluation [89]. Older adults exposed to negative stereotypes about age-related cognitive decline, show decreased memory performance [90]. Similarly, we see how having a stereotype hanging over you, a "stereotype threat," reduces your ability to perform. Those that had dementiaphobia underperformed on executive tasks. Just the fear reduces your ability to function to your normal level [91]. Fear itself reduces your ability. With a stereotype not only are you more likely to acquiesce, but others are more likely to support that stereotype once it is applied. When physicians read articles revealing that older adults with memory issues are likely to have dementia, they were more likely to diagnose older patients with memory problems as having dementia $(70 \%)$ rather than when they did not read about the stereotype (14\%) [92].

\section{Mediate}

Mediate can express or suppress dementia. Psychopathology of dementia can tip the scales from temporary memory lapses to progressive dementia. This explains why longer-lived people that live free from dementia, live in communities of similarly older people (Blue Zones) where such negative stereotypes do not exist [93]. A low level of social contacts promotes all types of dementia while high educational attainment and a range of leisure activities showed protection against dementia [94]. These protective features are part of the theory of "brain reserve" [95] referring to the ability to tolerate biological pathology in the brain without developing clinical symptoms. Psychopathology arbitrates the dis-ease. The concept of brain reserve illustrates the importance of psychology, where complex patterns of mental activity through life reduces the incidence of dementia [96], and where high motivational abilities - self-discipline, willpower, and diligence prevents cognitive decline [97] as well as improves verbal intelligence, education, and occupation [98]. A high purpose in life, by people over 80 years old, reduce the incidence of Alzheimer's disease 7 years later even after adjusting for education, and depression [99].

\section{CONCLUSION}

The catalyst that starts the psychopathology of dementia is when we stop learning. We do not seek novelty. We do not know why this happens, whether it is the final stages of our development through a comprehensive isomorphic representation and the belief that we know the answers 
already, or whether it is emotional, related to the loss of zest for life. One of the most consistent findings in the etiology of dementia is the emerging expression of apathy and depression as a prodrome of dementia [100], [101]. Apathy and depression highlight a perceptual change [102] with longterm consequences. Both apathy and depression express a lack of concern with the world around us and reduces our interest in learning. These emotions herald a change in our developmental trajectory. Elderly people with depression and apathy are more likely than their counterparts to develop dementia [103], [104]. Social learning slowly unhinges as we come to rely on established patterns of behavior and disregarding novelty. With less learning, memory since it is designed for learning, atrophies. This slow process takes decades to express as dementia. Memory loss becomes increasingly peripheral as we stop learning.

When short-term memory atrophies, we lose retrieval of memories that shape self-consciousness, self-knowledge, and self-image [105] the loss of self, in turn, reduces our motivation to learn [106]. Each change results in an incremental negative change in our cognition. We avoid activities that involve novelty-seeking - such as sharing, exchanging of ideas, and being social, all known to delay/prevent dementia [107]. In the same way that placebos change our biology and outcomes, nocebos and negative perceptual biases similarly bring about negative physical and biological changes [108]. There is no conflict with the biology of dementia, but there is an intimate interrelatedness. Psychopathology promotes negative biological changes [109] as much as biological changes promote negative cognition.

As with false memories [110], psychopathology follows a set pattern of validation. Dementia becomes promoted by how we feel, our emotions, in this case, apathy, depression, and the lack of interest in learning about the world around us that start a cascade of negative cognitive sequala. As there is a strong correlation between dementia and depression, early studies suggested that up to one in twelve patients with dementia was in fact caused by depression [111], [112]. However, as a result of better diagnostics, more recent studies suggest lower rates (less than 1\%) [113]. Still, one in ten individuals who are seeking evaluation may well have dementia caused and or promoted by depression and its corollary, apathy [114]. Our negative emotions regulate our perception and act as a nocebo that influences our biology.

In a review of cognition-oriented treatments [115], while the results were mixed, on balance greater depression predicted poorer cognitive functioning, and improvement in controlling depressive resulted in cognitive benefits. Addressing apathy and depression goes a long way in mitigating cascading negative cognitions. Such interventions work best in the early stages of dementia when people are still able and willing to adjust their behavior. Dealing with the nocebo and stereotype threat is the first step in counteracting the psychopathology of dementia.

The second step is to develop self-serving positive suggestions. This requires embracing novelty in all things in life, to embrace challenges. Perseverance for learning new skills that we are not comfortable with. The easiest example to achieve this is to have ever-evolving 5-year goals; write a book, learn a language, play an instrument, hike a bucket list, anything that is achievable but not completely comfortable, and not to give up [116]. When you feel like giving up, it is how your brain informs you that it is using too many resources to accomplish the new task, and therefore an indication that you are learning. We should embrace eudemonia - the Greek philosophy of earning our contentment by self-regulation - such an approach helps our psychology and our brain by giving us a sense of control [117]. The psychopathology of dementia is a lifespan etiology and requires not only lifestyle change but also psychological changes as well. A great expanse of unknowns remains to be explored in dementia research and the psychopathology of dementia provides a first alternative psychological theory of the etiology of dementia.

\section{ACKNOWLEDGMENT}

No conflict of interest is declared. No external funding was provided for this research.

\section{REFERENCES}

[1] C. R. Jack Jr, M. S. Albert, D. S. Knopman, G. M. McKhann, R. A. Sperling, M. C. Carrillo and C. H. Phelps, "Introduction to the recommendations from the National Institute on Aging-Alzheimer's Association workgroups on diagnostic guidelines for Alzheimer's disease," Alzheimer's \& Dementia 7(3): 257-262, 2011.

[2] C. R. Jack Jr, D. A. Bennett, K. Blennow, M. C. Carrillo, B. Dunn, S. B. Haeberlein and N. Silverberg, "NIA-AA research framework: toward a biological definition of Alzheimer's disease," Alzheimer's \& Dementia 14(4): 535-562, 2018.

[3] C. Hock, U. Konietzko, J. R. Streffer, J. Tracy, A. Signorell, B. MüllerTillmanns and R. M. Nitsch, "Antibodies against $\beta$-amyloid slow cognitive decline in Alzheimer's disease," Neuron 38(4): 547-554, 2003.

[4] K. Iqbal, F. Liu and C. X. Gong, "Alzheimer disease therapeutics: focus on the disease and not just plaques and tangles," Biochemical Pharmacology 88(4), 631-639, 2014.

[5] C. Holmes, D. Boche, D. Wilkinson, G. Yadegarfar, V. Hopkins, A. Bayer and J. A. Nicoll, "Long-term effects of A $\beta 42$ immunisation in Alzheimer's disease: follow-up of a randomised, placebo-controlled phase I trial," The Lancet 372(9634): 216-223, 2008.

[6] S. Gilman, M. Koller, R. S. Black, L. Jenkins, S. G. Griffith, N. C. Fox and J. M. Orgogozo, "Clinical effects of A $\beta$ immunization (AN1792) in patients with AD in an interrupted trial," Neurology 64(9): 15531562, 2005.

[7] A. J. Bayer, R. Bullock, R. W. Jones, D. Wilkinson, K. R. Paterson, L. Jenkins and S. Donoghue, "Evaluation of the safety and immunogenicity of synthetic A $\beta 42$ (AN1792) in patients with AD," Neurology 64(1), 94-101, 2005.

[8] B. N. Cuthbert, "The role of RDoC in future classification of mental disorders," Dialogues in Clinical Neuroscience 22(1): 81, 2020,

[9] H. A. Crystal, D. Dickson, P. Davies, D. Masur, E. Grober and R. B. Lipton, "The relative frequency of dementia of unknown etiology increases with age and is nearly $50 \%$ in nonagenarians," Archives of Neurology 57(5): 713-719, 2000.

[10] T. Polvikoski, R. Sulkava, L. Myllykangas, I. L. Notkola, L. Niinistö, A. Verkkoniemi and M. Haltia, "Prevalence of Alzheimer's disease in very elderly people: a prospective neuropathological study," Neurology 56(12): 1690-1696, 2001.

[11] R. Katzman, R. Terry, R. DeTeresa, T. Brown, P. Davies, P. Fuld and A. Peck, "Clinical, pathological, and neurochemical changes in dementia: a subgroup with preserved mental status and numerous neocortical plaques," Annals of Neurology: Official Journal of the American Neurological Association and the Child Neurology Society 23(2): 138-144, 1988.

[12] D. G. Davis, F. A. Schmitt, D. R. Wekstein and W. R. Markesbery, "Alzheimer neuropathologic alterations in aged cognitively normal subjects," Journal of Neuropathology and Experimental Neurology 58(4): 376-388, 1999.

[13] J. L. Price and J. C. Morris. "Tangles and Plaques in Nondemented Aging and "preclinical." Alzheimer's Disease. Annals of Neurology: Official Journal of the American Neurological Association and the Child Neurology Society 45(3): 358-68, 1999. 
[14] D. Knopman, "Pharmacotherapy for Alzheimer's Disease: 2002." Clinical Neuropharmacology 26(2), 93-101, 2002.

[15] D. A. Snowdon, L. H. Greiner, J. A. Mortimer, K. P. Riley, P. A. Greiner and W. R. Markesbery, "Brain infarction and the clinical expression of Alzheimer disease: the Nun Study," Jama 277(10), 813$817,1997$.

[16] D. W. Dickson, "Neuropathological Diagnosis of Alzheimer's Disease: A Perspective from Longitudinal Clinicopathological Studies." Neurobiology of Aging 18(4): 21-26, 1997.

[17] B. E. Tomlinson, G. Blessed and M. Roth, "Observations on the brains of demented old people," Journal of the Neurological Sciences 11(3): 205-242, 1970

[18] H. Braak, D. R. Thal, E. Ghebremedhin and K. Del Tredici, "Stages of the pathologic process in Alzheimer disease: age categories from 1 to 100 years," Journal of Neuropathology \& Experimental Neurology 70(11): 960-969, 2011.

[19] G. M. Savva, S. B. Wharton, P. G. Ince, G. Forster, F. E. Matthews and C. Brayne, "Age, neuropathology, and dementia," New England Journal of Medicine 360(22): 2302-2309, 2009.

[20] M. D. Garrett, Politics of Anguish: How Alzheimer's disease became the malady of the 21st century Createspace, 2015.

[21] D. E. Bredesen and V. John "Next Generation Therapeutics for Alzheimer's Disease," EMBO Mol Med 5(975), 2013.

[22] D. E. Bredesen, Reversal of Cognitive Decline: A Novel Therapeutic Program, Aging, Albany NY, 6(9), 2014.

[23] M. Kivipelto, A. Solomon, S. Ahtiluoto, T. Ngandu, J. Lehtisalo, R. Antikainen and H. Soininen, "The Finnish geriatric intervention study to prevent cognitive impairment and disability (FINGER): study design and progress," Alzheimer's \& Dementia 9(6): 657-665, 2013.

[24] M. Kivipelto, F. Mangialasche, H. M. Snyder, R. Allegri, S. Andrieu, H. Arai and M. C. Carrillo, "World-Wide FINGERS Network: a global approach to risk reduction and prevention of dementia," Alzheimer's \& Dementia 16(7): 1078-1094, 2020.

[25] M. Garrett, "Multiple Causes of Dementia as Engineered Senescence." European Journal of Medical and Health Science 2(2), 2020.

[26] I. G. McKeith, D. Galasko, K. Kosaka, E. K. Perry, D. W. Dickson, L. A. Hansen and R. H. Perry, "Consensus guidelines for the clinical and pathologic diagnosis of dementia with Lewy bodies (DLB): report of the consortium on DLB international workshop," Neurology 47(5): 1113-1124, 1996.

[27] C. F. Vahl, "Lewy Body and Parkinsonian Dementia: Common, but Often Misdiagnosed Conditions: Hydrocephalus Should Not Be Forgotten.Deutsches," Arzteblatt International 108(8): 131, 2011.

[28] J. S. Schiller, J. W. Lucas and J. A. Peregoy, "Summary Health Statistics for U.S. Adults:National Health Interview Survey, 2011,' National Center for Health Statistics Vital Health Stat 10(256), 2012.

[29] T. Wetterling, R. D. Kanitz and K. J. Borgis, "Comparison of different diagnostic criteria for vascular dementia (ADDTC, DSM-IV, ICD-10, NINDS-AIREN)," Stroke 27(1): 30-36, 1996.

[30] G. H. Brody, T. Yu, E. Chen, S. R. Beach and G. E. Miller, (2016). "Family-centered prevention ameliorates the longitudinal association between risky family processes and epigenetic aging," Journal of Child Psychology and Psychiatry 57(5): 566-574, 2016.

[31] I. Požgain, Z. Požgain and D. Degmečić, "Placebo and nocebo effect: a mini-review." Psychiatria Danubina 26(2): 0-107, 2014.

[32] I. E. Dror, I. C. Schmitz-Williams and W. Smith, "Older adults use mental representations that reduce cognitive load: mental rotation utilizes holistic representations and processing," Experimental Aging Research 31(4): 409-420, 2005.

[33] F. Blanchard-Fields, A. Mienaltowski and R. B. Seay, "Age differences in everyday problem-solving effectiveness: Older adults select more effective strategies for interpersonal problems," The Journals of Gerontology Series B: Psychological Sciences and Social Sciences, 62(1): 61-64, 2007.

[34] H. Shimada, H. Makizako, H. Park, T. Doi and S. Lee, "Validity of the National Center for Geriatrics and Gerontology-Functional Assessment Tool and Mini-Mental State Examination for detecting the incidence of dementia in older Japanese adults," Geriatrics \& Gerontology International 17(12): 2383-2388, 2017.

[35] M. Maltz and D. Shinar. "Eye Movements of Younger and Older Drivers." Human Factors 41(1): 15-25, 1999.

[36] D. J. Simons and C. F. Chabris. "Gorillas in Our Midst: Sustained Inattentional Blindness for Dynamic Events.” Perception 28(9): 105974, 1999.

[37] A. F. Williams and O. Carsten. "Driver Age and Crash Involvement." American Journal of Public Health 79(3), 326-27, 1989.

[38] S. M. Retchin and J. Anapolle, "An Overview of the Older Driver." Clinics in Geriatric Medicine 9(2): 279-96, 1993.
[39] J. M. Lyman, G. McGwin Jr and R.V. Sims, "Factors Related to Driving Difficulty and Habits in Older Drivers." Accident Analysis \& Prevention 33(3):413-21, 2001.

[40] T. D. Willstrand, T. Broberg and H. Selander, "Driving characteristics of older drivers and their relationship to the useful field of view test," Gerontology 63(2): 180-188, 2017.

[41] T. Fritsch, K. A. Smyth, S. M. Debanne, G. J. Petot and R. P. Friedland, "Participation in novelty-seeking leisure activities and Alzheimer's disease," Journal of Geriatric Psychiatry and Neurology 18(3): 134 $141,2005$.

[42] B. D. Glass, W. T. Maddox and B. C. Love, "Real-time strategy game training: emergence of a cognitive flexibility trait," Plos One 8(8): e70350, 2013.

[43] L. J. Tranter and W. Koutstaal, "Age and Flexible Thinking: An Experimental Demonstration of the Beneficial Effects of Increased Cognitively Stimulating Activity on Fluid Intelligence in Healthy Older Adults." Aging, Neuropsychology, and Cognition 15(2): 184-207, 2008.

[44] E. A. Stine-Morrow, J. M. Parisi, D. G. Morrow and D. C. Park, "The effects of an engaged lifestyle on cognitive vitality: a field experiment," Psychology and Aging 23(4): 778, 2008.

[45] M. C. Carlson, J. S. Saczynski, G. W. Rebok, T. Seeman, T. A. Glass, S. McGill and L. P. Fried, "Exploring the effects of an "everyday" activity program on executive function and memory in older adults: Experience Corps ${ }^{\circledR}, "$ The Gerontologist 48(6): 793-801, 2008.

[46] J. A. Bugos, W. M. Perlstein, C. S. McCrae, T. S. Brophy and P. H. Bedenbaugh, "Individualized piano instruction enhances executive functioning and working memory in older adults," Aging and Mental Health 11(4): 464-471, 2007.

[47] J. A. Mortimer, D. Ding, A. R. Borenstein, C. DeCarli, Q. Guo, Y. Wu and $\mathrm{S}$. Chu, "Changes in brain volume and cognition in a randomized trial of exercise and social interaction in a community-based sample of non-demented Chinese elders," Journal of Alzheimer's Disease 30(4), 757-766, 2012

[48] P. Fissler, O. Kuester, W. Schlee and I. T. Kolassa, "Novelty interventions to enhance broad cognitive abilities and prevent dementia: synergistic approaches for the facilitation of positive plastic change," Progress in Brain Research 207, 403-434, 2013.

[49] E. A. Maguire, K. Woollett and H. J. Spiers, "London taxi drivers and bus drivers: a structural MRI and neuropsychological analysis," Hippocampus 16(12): 1091-1101, 2006.

[50] M. Cappelletti, D. Didino, I. Stoianov and M. Zorzi, "Number skills are maintained in healthy ageing," Cognitive Psychology 69, 25-45, 2014.

[51] G. Deloche, D. Mannequin, S. Carlomagno, A. Agniel, M. Dordain, F. Pasquier and X. Seron, "Calculation and number processing in mild Alzheimer's disease," Journal of Clinical and Experimental Neuropsychology 17(4): 634-639, 1995.

[52] A. M. Kennedy, S. K. Newman, R. S. J. Frackowiak, V. J. Cunningham, P. Roques, J. Stevens and M. N. Rossor, "Chromosome 14 linked familial Alzheimer's disease: A clinico-pathological study of a single pedigree," Brain 118(1): 185-205, 1995.

[53] R. McGlinchey-Berroth, W. P. Milberg and N. Charness, "Learning of a complex arithmetic skill in dementia: Further evidence for a dissociation between compilation and production," Cortex 25(4): 697705, 1989.

[54] H. Diesfeldt, "Progressive Decline of Semantic Memory with Preservation of Number Processing and Calculation," Behavioural Neurology 6, 239-42, 1993.

[55] L. Girelli and M. Delazer, "Numerical abilities in dementia." Aphasiology 15(7), 681-94, 2001.

[56] P. Wallich, "Senile Words." Scientific American 274(6), 26-27, 1996.

[57] S. Daigneault, C. M. Braun and H. A. Whitaker, "Early effects of normal aging on perseverative and non-perseverative prefrontal measures," Developmental Neuropsychology 8(1): 99-114, 1992.

[58] P. K. Kuhl, "Early Language Acquisition: Cracking the Speech Code." Nature Reviews Neuroscience 5(11): 831-43, 2004.

[59] O. Pascalis, L. S. Scott, D. J. Kelly, R. W. Shannon, E. Nicholson, M Coleman and C. A. Nelson, "Plasticity of face processing in infancy," Proceedings of the National Academy of Sciences 102(14): 5297-5300, 2005.

[60] T. P. German and M. A. Defeyter. "Immunity to Functional Fixedness in Young Children," Psychonomic Bulletin and Review 7(4): 707-12, 2000.

[61] C. G. Lucas, S. Bridgers, T. L. Griffiths and A. Gopnik, "When children are better (or at least more open-minded) learners than adults: Developmental differences in learning the forms of causal relationships," Cognition 131(2): 284-299, 2014.

[62] P. H. Miller, Piaget's Theory: Past, Present, and Future 2011.

[63] T. Metitieri, O. Zanetti, C. Geroldi, G. B. Frisoni, D. De Leo, M. D. Buono and M. Trabucchi, "Reality orientation therapy to delay 
outcomes of progression in patients with dementia. A retrospective study," Clinical Rehabilitation 15(5): 471-478, 2001.

[64] C. Jonker, M. I. Geerlings and B. Schmand, "Are memory complaints predictive for dementia? A review of clinical and population-based studies," International Journal of Geriatric Psychiatry 15(11): 983991, 2000.

[65] S. Hamann, "Cognitive and neural mechanisms of emotional memory." Trends in Cognitive Sciences 5, 394-400, 2001.

[66] E. A. Kensinger, "Remembering Emotional Experiences: The Contribution of Valence and Arousal." Reviews in the Neurosciences 15(4), 241-52, 2004.

[67] K. S. LaBar and R. Cabeza. "Cognitive Neuroscience of Emotional Memory." Nature Reviews Neuroscience 7, 54-64, 2006.

[68] L. J. Levine, "Reconstructing Memory for Emotions." Journal of Experimental Psychology: General 126(2), 165-77, 1997.

[69] H. Schmolck, E. A. Buffalo and L. R. Squire, "Memory distortions develop over time: Recollections of the OJ Simpson trial verdict after 15 and 32 months," Psychological Science 11(1): 39-45, 2000.

[70] J. M. Talarico and D. C. Rubin. "Confidence, not consistency, characterizes flashbulb memories." Psychological Science 14(5): 455$61,2003$.

[71] K. A. Deffenbacher and E. F. Loftus, "Do jurors share a common understanding concerning eyewitness behavior?" Law and Human Behavior 6(1): 15-30, 1982.

[72] A. M. Glenberg, "What Memory Is For." Behavioral and Brain Sciences 20(1): 1-19, 1997.

[73] H. Merckelbach, M. Dalsklev, D. van Helvoort, I. Boskovic and H. Otgaar, "Symptom self-reports are susceptible to misinformation," Psychology of Consciousness: Theory, Research, and Practice 5(4): 384, 2018.

[74] H. Merckelbach, M. Jelicic and C. Jonker, "Planting a misdiagnosis of Alzheimer's disease in a person's mind." Acta Neuropsychiatrica, 24(1), 60-62, 2012.

[75] K. H. Campbell, C. B. Stocking, G. W. Hougham, P. J. Whitehouse, D. D. Danner and G. A. Sachs, "Dementia, diagnostic disclosure, and selfreported health status," Journal of the American Geriatrics Society 56(2): 296-300, 2008.

[76] S. A. Wolf, M. Henry, R. Deike, A. D. Ebert and C. W. Wallesch, "Verdachtsdiagnose Alzheimer-Demenz," Der Nervenarzt 79(4): 444453, 2008.

[77] M. Ross, "Relation of Implicit Theories to the Construction of Personal Histories." Psychological Review 96(2), 341, 1989.

[78] M. Conway, "On Bias in Autobiographical Recall: Retrospective Adjustments Following Disconfirmed Expectations." The Journal of Social Psychology 130(2): 183-89, 1990.

[79] L. V. Karnatovskaia, K. L. Philbrick, A. M. Parker and D. M. Needham, "Early psychological therapy in critical illness," Respiratory and Critical Care Medicine 37(1): 136-142, 2016.

[80] A. K. Szilágyi, C. Diószeghy, L. Benczúr and K. Varga, "Effectiveness of psychological support based on positive suggestion with the ventilated patient," European Journal of Mental Health 2(2), 149, 2007.

[81] A. K. Szilágyi, C.Diószeghy, G. Fritúz, J. Gál and K. Varga, "Shortening the length of stay and mechanical ventilation time by using positive suggestions via MP3 players for ventilated patients," Interventional Medicine and Applied Science 6(1): 3-15, 2014.

[82] U. NIlsson, N. Rawal, B. Enqvist and M. Unosson, "Analgesia following music and therapeutic suggestions in the PACU in ambulatory surgery; a randomized controlled trial," Acta Anaesthesiologica Scandinavica 47(3): 278-283, 2003.

[83] A. H. Lebovits, R. Twersky and B. McEwan, "Intraoperative therapeutic suggestions in day-case surgery: are there benefits for postoperative outcome?" British Journal of Anaesthesia 82(6): 861866, 1999.

[84] T. McLintock, H. Aitken, C. F. Downie and G. N. Kenny, "Postoperative analgesic requirements in patients exposed to positive intraoperative suggestions," British Medical Journal 301(6755): 788$790,1990$.

[85] J. Schlanger, G. Fritúz and K. Varga, "Therapeutic suggestion helps to cut back on drug intake for mechanically ventilated patients in intensive care unit," Interventional Medicine and Applied Science 5(4): 145-152, 2013.

[86] K. Thorsen, M. C. N. Dourado and A. Johannessen, "Developing dementia: the existential experience of the quality of life with youngonset dementia-a longitudinal case study," Dementia 19(3): 878-893, 2020.

[87] C. R. Weinert, C. R. Gross, J. R. Kangas, C. L. Bury and W. A. Marinelli, "Health-related quality of life after acute lung injury," American Journal of Respiratory and Critical Care Medicine 156(4): 1120-1128, 1997.
[88] A. Koppara, M. Wagner, C. Lange, A. Ernst, B. Wiese, H. H. König and F. Jessen, "Cognitive performance before and after the onset of subjective cognitive decline in old age," Alzheimer's \& Dementia: Diagnosis, Assessment \& Disease Monitoring 1(2): 194-205, 2015.

[89] D. D. Brigham and P. O. Toal, "The Use of Imagery in a Multimodal Psychoneuroimmunology Program for Cancer and Other Chronic Diseases." Mental Imagery, 193-98, 1990.

[90] T. M. Hess, C. Auman, S. J. Colcombe and T. A. Rahhal, "The impact of stereotype threat on age differences in memory performance," The Journals of Gerontology Series B: Psychological Sciences and Social Sciences 58(1): 3-11, 2003.

[91] M. Fresson, B. Dardenne, M. Geurten and T. Meulemans, "The effect of stereotype threat on older people's clinical cognitive outcomes: Investigating the moderating role of dementia worry," The Clinical Neuropsychologis, 31(8): 1306-1328, 2017.

[92] C. Haslam, T. A. Morton, S. A. Haslam, L. Varnes, R. Graham and L. Gamaz, "When the age is in, the wit is out: Age-related selfcategorization and deficit expectations reduce performance on clinical tests used in dementia assessment," Psychology and Aging 27(3): 778, 2012.

[93] D. Buettner, The Blue Zones: 9 Lessons for Living Longer from the People Who've Lived the Longest, National Geographic Books, 2012.

[94] V. Bellou, L. Belbasis, I. Tzoulaki, L. T. Middleton, J. P. Ioannidis and E. Evangelou, "Systematic evaluation of the associations between environmental risk factors and dementia: an umbrella review of systematic reviews and meta-analyses," Alzheimer's \& Dementia 13(4): 406-418, 2017.

[95] L. Fratiglioni and H. X. Wang, "Brain Reserve Hypothesis in Dementia." Journal of Alzheimer's Disease 12(1): 11-22, 2007.

[96] M. J. Valenzuela and P. Sachdev. "Brain reserve and dementia: a systematic review." Psychological Medicine 36(4): 441,2006.

[97] S. Forstmeier, A. Maercker, W. Maier, H. Van Den Bussche, S. RiedelHeller, H. Kaduszkiewicz and M. Wagner, "Motivational reserve: motivation-related occupational abilities and risk of mild cognitive impairment and Alzheimer disease," Psychology and Aging 27(2): 353, 2012.

[98] S. Forstmeier and A. Maercker, "Motivational Reserve: Lifetime Motivational Abilities Contribute to Cognitive and Emotional Health in Old Age." Psychology and Aging 23(4),886, 2008.

[99] P. A. Boyle, A. S. Buchman, L. L. Barnes and D. A. Bennett, "Effect of a purpose in life on risk of incident Alzheimer disease and mild cognitive impairment in community-dwelling older persons," Archives of General Psychiatry 67(3): 304-310, 2010.

[100]M. A. Bock, A. Bahorik, W. D. Brenowitz and K. Yaffe, “Apathy and risk of probable incident dementia among community-dwelling older adults," Neurology 95(24): e3280-e3287, 2020.

[101]R. L. Ownby, E. Crocco, A. Acevedo, V. John and D. Loewenstein, "Depression and risk for Alzheimer disease: systematic review, metaanalysis, and metaregression analysis," Archives of General Psychiatry 63(5): 530-538, 2006.

[102]A. Mowla, H. Ashkani, A. Ghanizadeh, G. R. Dehbozorgi, B. Sabayan and A. H. Chohedri, "Do memory complaints represent impaired memory performance in patients with major depressive disorder?" Depression and Anxiety 25(10): E92-E96, 2008.

[103]D. P. Devanand, M. Sano, M. X. Tang, S. Taylor, B. J. Gurland, D. Wilder and R. Mayeux, "Depressed mood and the incidence of Alzheimer's disease in the elderly living in the community," Archives of General Psychiatry, 53(2): 175-182, 1996.

[104]R. A. Sweet, R. L. Hamilton, M. A. Butters, B. H. Mulsant, B. G. Pollock, D. A. Lewis and C. F. Reynolds, "Neuropathologic correlates of late-onset major depression," Neuropsychopharmacology 29(12): 2242-2250, 2004.

[105]M. El Haj, P. Antoine, J. L. Nandrino and D. Kapogiannis, "Autobiographical memory decline in Alzheimer's disease, a theoretical and clinical overview," Ageing Research Reviews 23, 183$192,2015$.

[106]M. Amanzio, G. Geminiani, D. Leotta and S. Cappa, "Metaphor comprehension in Alzheimer's disease: Novelty matters," Brain and Language 107(1): 1-10, 2008.

[107]C. Stern and Z. Munn. "Cognitive Leisure Activities and Their Role in Preventing Dementia: A Systematic Review," International Journal of Evidence-Based Healthcare 8(1), 2-17, 2010.

[108]P. Enck, F. Benedetti and M. Schedlowski, "New insights into the placebo and nocebo responses," Neuron 59(2): 195-206, 2008.

[109]F. Benedetti and A. Shaibani, "Nocebo effects: more investigation is needed," Expert Opinion on Drug Safety 17(6): 541-543, 2018.

[110]E. Loftus, "The Fiction of Memory," 2020.

[111]A. M. Clarfield, "The Reversible Dementias: Do They Reverse?" Ann Intern Med 109(6): 476-86, 1988. 
[112]M. D. Weytingh, P. M. M. Bossuyt and H. Van Crevel, "Reversible dementia: more than $10 \%$ or less than $1 \%$ ?" Journal of Neurology 242(7): 466-471, 1995.

[113]M. A. Clarfield, "The Decreasing Prevalence of Reversible Dementias: An Updated Meta-Analysis." Arch Intern Med 163(18), 2219-29, 2003.

[114]A. Hejl, P. Høgh and G. Waldemar, "Potentially reversible conditions in 1000 consecutive memory clinic patients," Journal of Neurology, Neurosurgery \& Psychiatry 73(4): 390-394, 2002.

[115]S. L. Webb, D. P. Birney, V. Loh, S. Walker, A. Lampit and A.BaharFuchs, "Cognition-oriented treatments for older adults: A systematic review of the influence of depression and self-efficacy individual differences factors," Neuropsychological Rehabilitation 1-37, 2001.

[116]M. S. Hagger, C. Wood, C. Stiff and N. L. Chatzisarantis, "Ego depletion and the strength model of self-control: a meta-analysis," Psychological Bulletin 136(4): 495, 2010.

[117]A. M. F. J. N. Johannes and O. Ritter, "Psychological consequences of longevity," Human Development 52, 1-37, 2009.

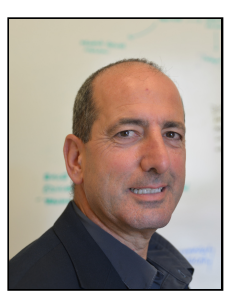

Mario Dominic Garrett, Ph.D., is professor of gerontology at San Diego State University, California, USA. Prof. Garrett founded the International Journal on Ageing in Developing Countries and with the Minority Aging Research Institute at University of North Texas, coordinated a statewide study in all the nineteen pueblos in New Mexico. He founded and maintained a Monograph series on Indian health for the National Indian Council on Aging with eight series published. After joining the faculty at San Diego State University in 2004 , he was the chairman of the department of gerontology and directed three research institutes.

Professor Garrett has just published Coming of Age in Film with Cambridge Scholar Publishing and Social Dementia: The Role of Memory with Kindle. 